Asian Journal of Medical and Biological Research ISSN 2411-4472 (Print) 2412-5571 (Online) https://www.ebupress.com/journal/ajmbr/

\title{
Article \\ Constrains and determinants for improvement of rural livelihood in the coastal community of Bangladesh
}

Tusher Chakrobarty ${ }^{1}$, Shahin Imran ${ }^{2}$, Md. Asif Mahamud ${ }^{3 *}$, Md. Musfiqur Rahman ${ }^{4}$, Md. Golam Rahman ${ }^{4}$, Jhutan Chandra Sarker ${ }^{4}$, Md. Rezaul Karim ${ }^{4}$, Md. Niaz Morshed ${ }^{5}$, Md. Al Emran Hossain ${ }^{5}$, Naim Mustafa Ali ${ }^{6}$ and Golam Mustafa Chowdhury ${ }^{7}$

${ }^{1}$ Bangladesh Rice Research Institute, Regional Station, Bhanga, Faridpur, Bangladesh

${ }^{2}$ Department of Agronomy, Khulna Agricultural University, Khulna-9100, Bangladesh

${ }^{3}$ Department of Agricultural Chemistry, Khulna Agricultural University, Khulna-9100, Bangladesh

${ }^{4}$ Bangladesh Agricultural Research Institute, Gazipur, Bangladesh

${ }^{5}$ Bangladesh Sugarcrop Research Institute, Ishwardi, Pabna, Bangladesh

${ }^{6}$ Bangladesh Tea Research Institute, Srimangal-3210, Moulvibazar, Bangladesh

${ }^{7}$ Bangladesh Forest Research Institute, Chattogram, Bangladesh

*Corresponding author: Md. Asif Mahamud, Department of Agricultural Chemistry, Khulna Agricultural University (KAU), Khulna-9100, Bangladesh. Phone: +8801738-341720; E-mail: asifmahamud@ kau.edu.bd

Received: 14 November 2021/Accepted: 12 December 2021/ Published: 30 December 2021

Copyright (C) 2021 Tusher Chakrobarty et al. This is an open access article distributed under the Creative Commons Attribution 4.0 International License (https://creativecommons.org/licenses/by/4.0/), which permits unrestricted use, distribution, and reproduction in any medium, provided the original work is properly cited.

\begin{abstract}
Agriculture farmers face abundant risk for crop cultivation at rural area of Bangladesh. About 85\% of population in coastal region of Bangladesh, Dumki upazila, related to agriculture for livelihood directly or indirectly. To mitigate the problem facing by the farmers, there are available a lots of climate smart technologies. However, different demographic, socio-economic, production, management and post-harvest determinants influences the adoption of these modern technologies. This study focuses on the identification of farmer's socio-economic condition, their knowledge, attitude, and perception on improvement of existing livelihood based on selected personal and demographic variables. Both primary and secondary data has been collected from different sources to fulfill the objectives. The results of this study indicated that the farmer's age, education level and farming experiences significantly influence the adoption of modern technologies. Farmer's knowledge, perception and attitude differ on different demographic condition like, age, sex, education, farm size, farming year. Results also showed that lacking of quality seeds, lacking/high price of labor and other inputs for crop production hastens the adoption of modern technologies. This study provides some recommendation which might impacts on betterment of farmers' occupational condition by establishing proper policy and legislation both in local and national level.
\end{abstract}

Keywords: Dumki upazila; rural livelihood; smart technologies; socio-economic; farming experience

\section{Introduction}

The economy of Bangladesh is predominantly dependent on agriculture. Agriculture is the prime producing sector of the economy which has significant importance for achieving sustainable food and livelihood security in large, dense and ever-growing population of Bangladesh (World Bank, 2016). In addition, it is the major source of livelihood in rural areas where most of the people live in. FAO (2014) reported that the agricultural and rural sector in Bangladesh has imposed a great impact on a macro-economic situation like employment 
generation, poverty alleviation, food security and nutritional enrichment etc. The land ownership size of Bangladeshi farmers is classified into landless (up to 0.5 acre), marginal (0.51 to 1.00 acre), small (1.01 to 2.5 acres), medium (2.51 to 5.00 acres), large (5.01 acres and above) (BBS, 2010; Quasem, 2011). The Dumki upazila of Patuakhali district is recognized as the area of food surplus due to the diversity of crop and adaptation of improved agricultural technologies (Hossain et al., 2015). In contrast, rainfed along with tidal water-based crop production is practiced in this upazila (Hossain et al., 2015; Rashid, 2020). The farmers of Dumki upazila are used to grow low yielding traditional photosensitive varieties (local Sadamota, lalmota, dhudkolom, moulata variety in Aman rice) and frequency is comparatively high (Hossain et al., 2015; Islam, 2017). The intensity of natural disaster is rapidly escalating due to climate change and it becomes a severe problem in the coastal region of Bangladesh. Tropical cyclones that form in the Bay of Bengal hits Bangladesh coast twice in a year, the most severe ones occurring in late October to mid-November and late April to May coincide with the harvesting time of major cereals (Kabir, 2016; Awal and Khan, 2020). This is the main drawbacks of the farming communities in this region to maintain their food security.

For improvement of rural livelihood, the problems are confronted by the farmers that differs from farmer to farmer due to several factors e.g., personal, social, economic and phycological characteristics (Rahman et al., 2016; Mondal et al., 2020). These facts indicate the needs a prudent research survey to understand the problems confrontation and relationship with their different factors at Dumki upazila in Patuakhali district.

The objectives of this study were as follows:

I. To delineate the socio-economic conditions of the farmers and their farming characteristics.

II. To explore the relationship between selected characteristics and crop productivity.

III. To identify the problems faced by the farmers in agricultural production.

\section{Materials and Methods}

\subsection{Study area}

The research study was carried out at Dumki upazila, Patuakhal, Bangladesh (Figure 1). It is located in between $22^{\circ} 23^{\prime}$ and $22^{\circ} 30^{\prime}$ north latitudes and in between $90^{\circ} 17^{\prime}$ and $90^{\circ} 27^{\prime}$ east longitudes. It is bounded by Bakerganj upazila on the north, Patuakhali sadar and Bauphal upazilas on the south, Bauphal upazila on the east, Mirzaganj upazila on west. There are 5 Unions in the Dumki upazila named by Angaria, Labukhali, Muradia, Pangasia, and Sreerampur having an area of 92.41 sq.km.

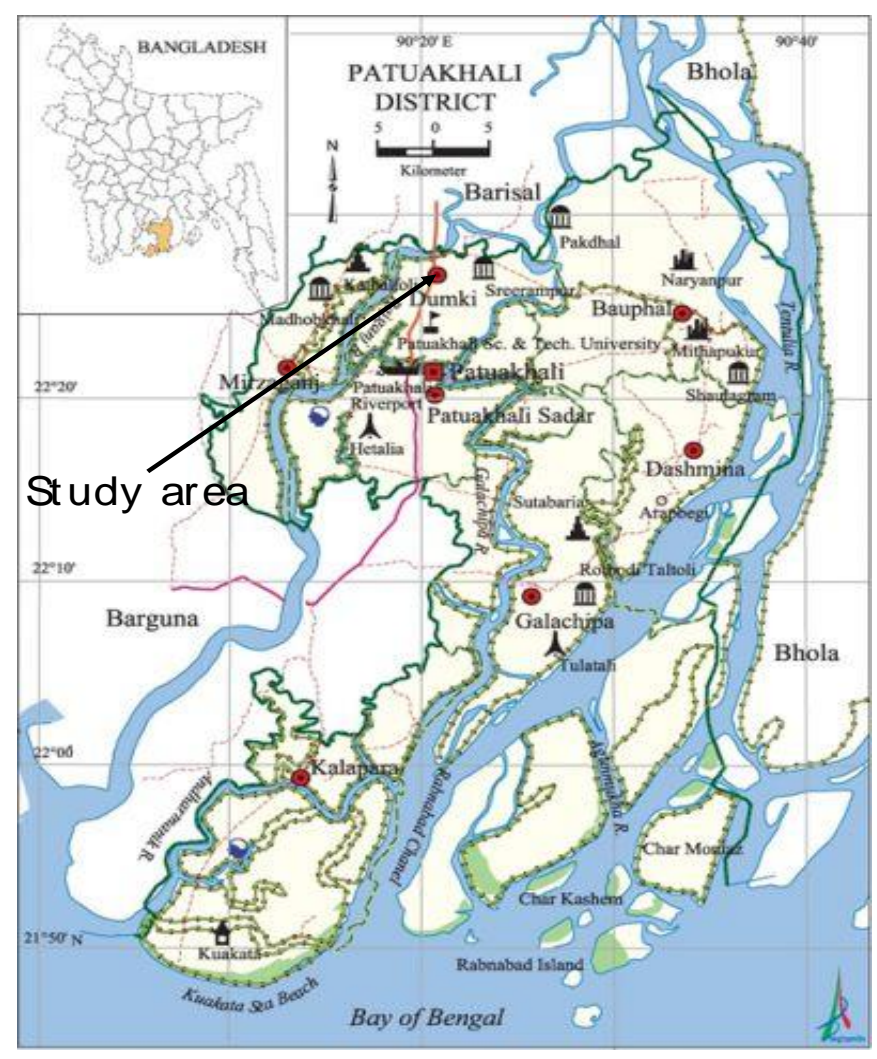

Figure 1. Location of the study area: the Dumki upazila. 


\subsection{Climate of study area}

It has a tropical monsoon climate as the whole Bangladesh prevails the same. Rain water is the major source for agricultural crop cultivation in this area. The monsoon prevails from May to October and 90 percent of the annual rainfall occurs during this period. The average annual humidity is $84 \%$ and it remains high in monsoon and the heavy precipitation during the months of April to September and scanty rainfall during the months of October to March. Maximum temperature is prevailed at $35.3^{\circ} \mathrm{C}$ and minimum at $12.1{ }^{\circ} \mathrm{C}$; annual rainfall is approximately $2506 \mathrm{~mm}$ (Banglapedia, 2008).

\subsection{Cropping patterns of the study area}

Different crop varieties are grown in Bangladesh but the rice is considered as dominant crop in terms of land use and production. Rice alone accounts for about 75 per cent of the cropping area in the country (Quasem, 2011; Ghose, 2014). According to Department of Agriculture Extension (DAE) secondary data, majority farmers of Dumki upazila follow Mungbean-Fallow-T.Aman cropping pattern. Transplanted Aman is the principal crop throughout the region. Aus and Rabi crops (mainly grass pea, lentil, sweet potato, bean and chilli) are widely grown in non-saline areas. Other crops are sunflower, wheat, onion, cucumber, gherkin, watermelon, betel leaf, vegetables etc (Table 1). The study area comprises different proportion of cropped area (Figure 2). Using different cropped area, the cropping intensity of Dumki upazila was estimated at $222 \%$.

Cropping intensity $(\%)=\frac{(\text { Three cropped area } \times 3)+(\text { two cropped area } \times 2)+(\text { Single Cropped area } \times 1)}{\text { Total cropped area }}$

Cropping Intensity $(\%)=((2195 \times 3)+(4130 \times 2)+(465 \times 1)) / 6900 \times 100=222 \%$

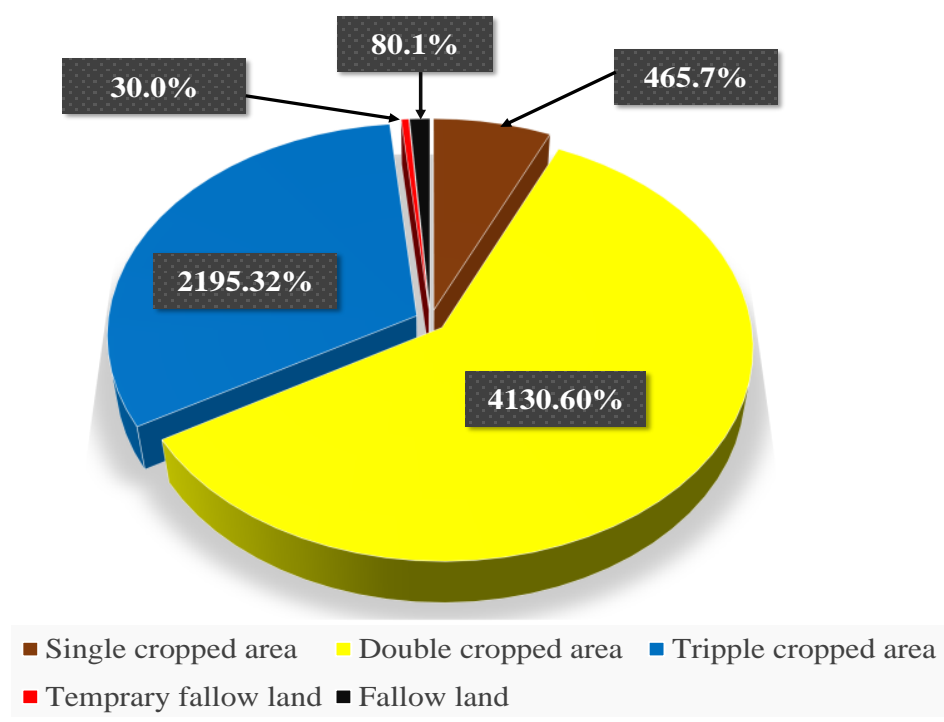

Figure 2. Land use patterns in Dumki upazila.

\subsection{Sampling the population}

Landless, small and medium farmers involved in crop production were constituted the study population. The number of landless, small and medium farmers in this upazila is 3093, 4270 and 5630 respectively which reflect $88.43 \%$ of total farmers. Considering the farmers category, the farmer list was constructed with the help of Upazila Agriculture Office. A sample population was formulated by taking 50 farmers in each category.

\subsection{Data collection method}

Some secondary data was collected from different organization and online to make the delineation more vivid to researcher. For data collection, a set of interview schedule was designed for this study. Both close and open questions were used in the questionnaire. The questionnaire interviews were conducted at the pre-selected sites in the study area. Before going to make an actual interview, a brief introduction about the objective of the study was given to each of the farmers and assured them that all information would be kept confidential. Each question was explained clearly and asked systematically for their clear understanding. Different variable description and unit of measurement (Age, education, family size, family income, family expenditure status, 
farm size, experiences, source and level of income, status and source of loan, members participation in decision making, facing problems for rural development) was take into account.

\subsection{Data processing and analysis}

After data collection, these were verified to eliminate errors and inconsistencies. Any kind of inconsistencies in collected data were searched and discarded from the data. Data were processed and finally analyzed using descriptive statistics by Statistical tools for agricultural research software (STAR 2013). The data of local units were converted into international unit before analysis.

\section{Results and Discussion}

\subsection{Demographics of farmers}

\subsubsection{Age, farming experience, family size, land distribution}

Age of one hundred and fifty farmers was varied from 21 to 85 . The range is 24-85, 28-75, 21-70 for landless, marginal and small category farmers respectively. Farming experiences are almost same to all categories which is ranged between 5-30 years (Figure 3). A family size has been defined as the total number of persons of either sex living together and taking meals from the same kitchen under the administration of a single head of the family. The average family member in all categories is near to 5 (five) respondents were under medium sized family where 1 to 9 members exist (Figure 3). Considering all farm categories, family size was averaged from the 50 questionnaires of each category. Here landless family have average 4.8 members per family, marginal have 5.1 members per family and small have 5.2 members per family (Figure 3). The most of the respondents had small to medium sized family. Similar finding was observed by (Islam, 2018) and (Haque, 1995). The national average family size of Bangladesh is 4.50 members (HIES, 2010).
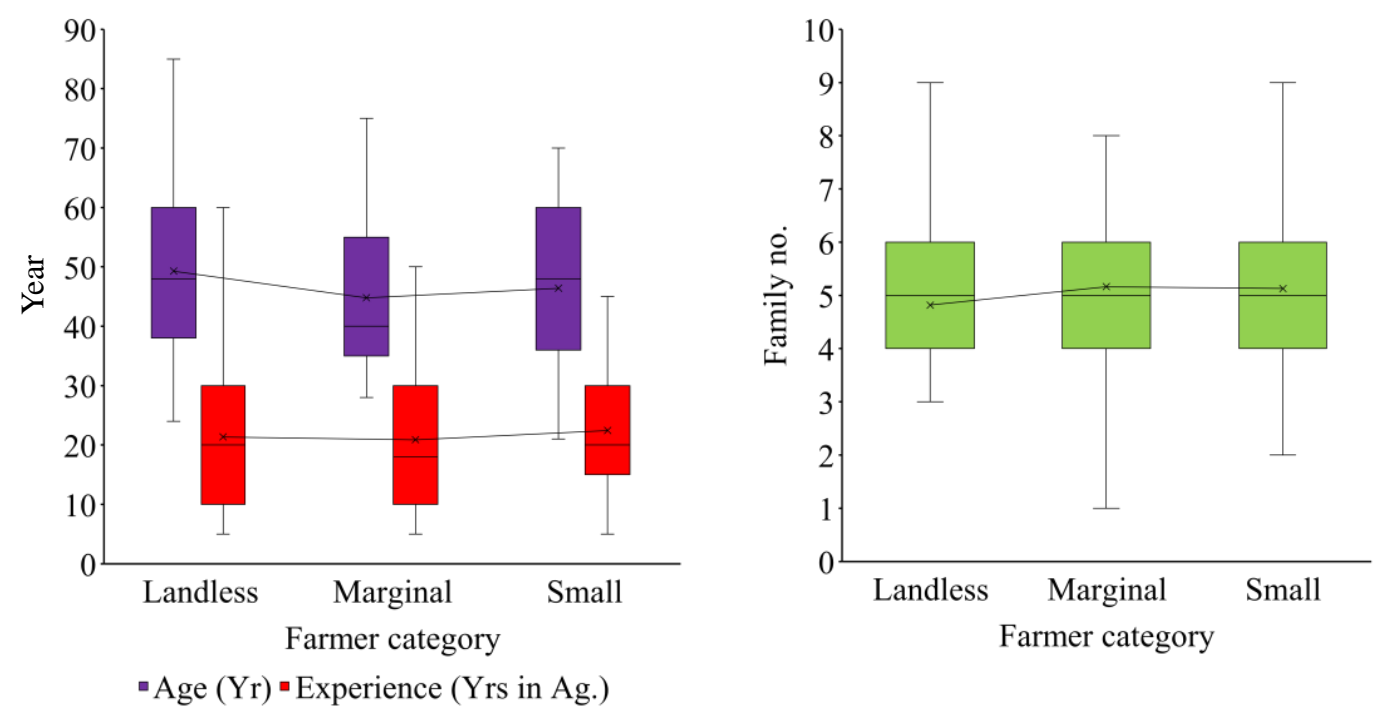

\section{Figure 3. Age, farming experience, family size of three categories farmers.}

\subsubsection{Educational status of farmers' family}

From the study it was found that educational status of farmers' family varied from Illiterate to Hon's level and it is observed that most of the families were poor educated that anchored with (Rashid, 2011) and (Biswas, 2015). Data of 150 farmers were averaged category wise.

In case of landless farmer, $27 \%$ family members have no formal education, $28 \%$ have primary education (class I to class $\mathrm{V}$ ), $28 \%$ members have secondary education (class VI to class $\mathrm{X}$ ) and $16 \%$ members are of higher education (HSC to Honors) (Figure 4)

In case of marginal farmers, $26 \%$ family members have no formal education, $29 \%$ have primary education (class I to class V), $26 \%$ members have secondary education (class VI to class X) and 17\% members are of higher education (HSC to Honors) (Figure 4).

In case of small farmers, $25 \%$ family members have no formal education, $27 \%$ have primary education (class I to class V), $28 \%$ members have secondary education (class VI to class $\mathrm{X}$ ) and $18 \%$ members are of higher education (HSC to Honors) (Figure 4). 

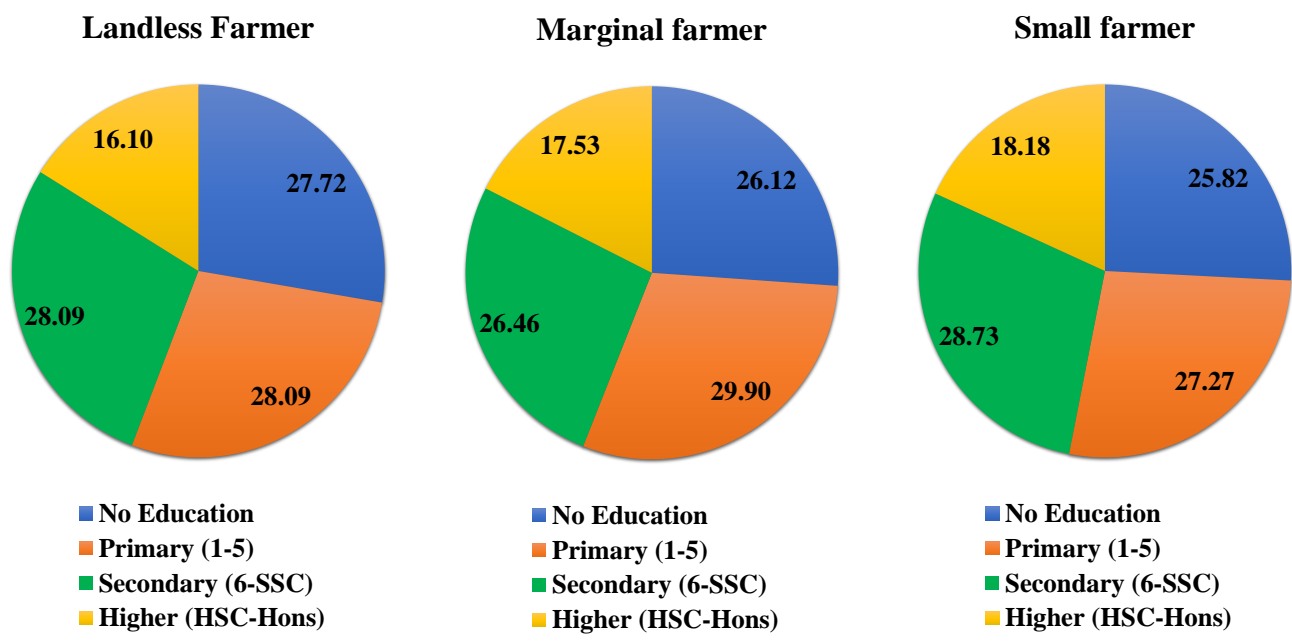

Figure 4. Educational status of three categories farmers family.

\subsubsection{Average family income of the sample farmers}

Yearly income was calculated from non-agriculture (business, job, labor etc.) and agricultural sources (field crops, vegetables, fruits, livestock and fisheries). According to the survey data, it was found that annual family average income from agricultural sources was TK. 66758, 99,909 and 114,818 landless, marginal and small category farmers respectively (Table 3, 4, 5). The income range/month (15000-20000 TK) is highest number of respondents $(56 \%)$ was observed in small categories followed by (15000-20000 TK) 38\% in marginal and (10000-15000 Tk) $46 \%$ in small farmers. Findings again revealed that most (44.7\%) of the respondents had 15000-20000 TK monthly income (Table 2). Maximum income came from labor in non-agricultural sector which range was 35000-100000 Tk, 40000-120000 Tk and 0-95000 Tk in landless, marginal and small categories farmers respectively. From agricultural sector, the landless farmers income was highest obtained from livestock (maximum 80000), the marginal and small farmers income was highest 13000-130000, 8000120000 Tk annually in grains production. (Figure 5). Relevant finding was found in the conducted study by researcher (Mondal, 2020).
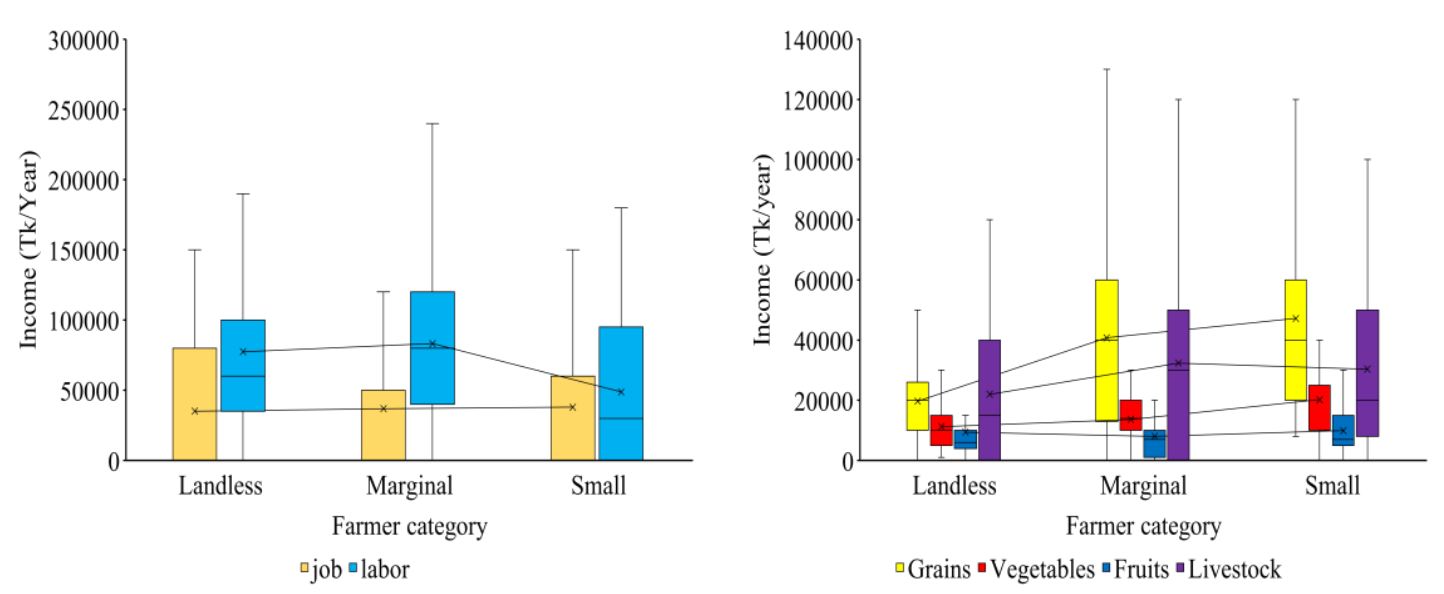

Figure 5. Prioritized fragmented income from non-agricultural and agricultural sector.

\subsection{Expenditure status and distribution}

The chronological order of highest expenditure status is marginal $\rightarrow$ small $\rightarrow$ landless. The amount was $244,272 \pm 18,960,222,185 \pm 18,004,218,676 \pm 18,796$ respectively. The famers of all three categories spent their high amount of money to buy food. The range was 40000-180000 Tk annually (Figure 6, Table 3, Table 4 and Table 5). 


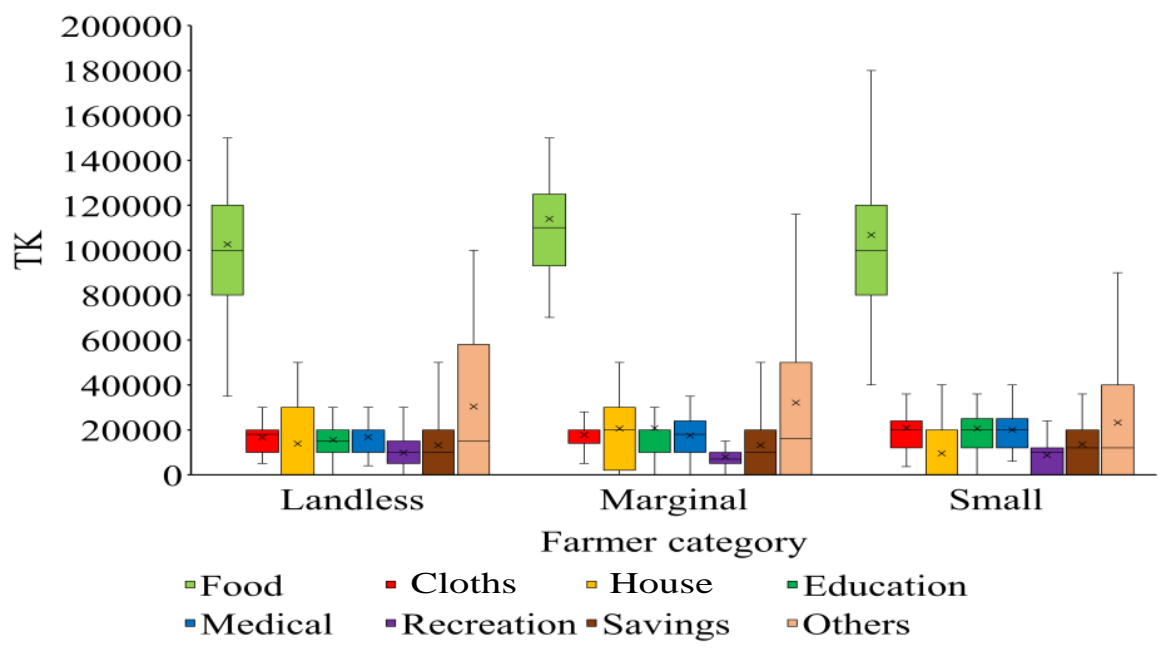

Figure 6. Expenditute and distribution of landless, marginal and small categories farmers.

\subsection{Accommodation facility}

Most of the landless and marginal farmers live in teen shade house consisting of four rooms having toilet and electricity facility. Most of them having their own tube well for drink water and other uses. But they don't use any solar electricity. In contrary, the house having five rooms and other facility are almost same as that's of landless and marginal farmers.

\subsection{Living Status of respondents}

Maximum farmers use safe drinking water and they have electricity and toilet facilities. The entire farmer uses digital technologies like mobile, television etc.

\subsection{Source of agricultural inputs}

Most of the farmers collect agricultural inputs from market. Some are collected from their relative/ other farmer and their own effort. Very few farmers were getting the opportunity of government aid.

\subsection{Extension contacts}

Most of the farmers visited to extension officials and different booklet, newspapers etc. from agricultural fair and demonstration and watched TV frequently. Some farmers went to agriculture activities, dealers occasionally. Very few farmers went to BADC officials.

\subsection{Adaptation of improved technology}

Farmers were willing to take the modern technology. Integrated pest management (IPM), sex pheromone trap, balanced fertilizer, were the mostly used technology for crop production. As the area is low lying, they use "Sorjan technology" for vegetable cultivation.

\subsection{Participation of agriculture training program}

Eighty-seven farmers got agriculture training programs from department of agriculture extension about production technology of modern rice, vegetables production in homestead area, integrated crop cultivation and fertilizer management. Training duration is 1 to 3 days.

\subsection{Preferred day for consultation}

Most of the farmers were gave their opinion to cooperate with responsible agricultural personnel every Friday followed by Sunday, and Saturday at 11:00am or 5:00 pm in every week. Some farmers have no preference about the day and time. Actually, they involve in agricultural work at morning and after 11:00 am are available.

\subsection{Status of homestead cultivation}

Homestead vegetable production mostly depends on the climatic and edaphic factors. In case of edaphic i.e., land classification, land profile, drainage system of the land etc. are the major factor for the selection of crop 
suitability. The study area, Dumki upazila of Patuakhali district is medium high land area and for this reason, rice covers most of the total arable lands. Other crops are potato, bitter gourd, bottle gourd, chili, ladies' figure, spinach, sweet gourd, cauliflower, bean, cabbage etc. winter and summer vegetables are grown in the homestead area.

\subsection{Problems faced by the farmers during crop production}

Through the interview, schedule researcher enlisted and ranked 15 main problems which were faced by the farmers during crop production. The problems were given in Table 6.

Table 1. List of different cropping pattern are practiced in Dumki upazila.

\section{SI. Cropping pattern (C.P.)}

No.

1. Mung- T. Aus- T. Aman

2. Grass pea- Fallow- T. Aman

3. Mung-Fallow- T. Aman

4. Grass pea- T. Aus - T. Aman

5. Fallow-Fallow- T. Aman

6. Fallow-Aus- T. Aman

7. Chilli-T. Aus- T. Aman

8. Winter Vegetables-Summer Vegetables- Summer Vegetables

9. Sesame- Fallow- T. Aman

10. Boro- Fallow- T. Aman

11. Sweet Potato- Fallow- T. Aman

12. Lentil - Fallow $-\mathrm{T}$. aman

13. Maize- Fallow- T. Aman

14. Potato - Fallow- T. Aman

15. Sunflower - Fallow- T. Aman

16. Cowpea - Fallow- T. Aman

17. Gram- Fallow- T. Aman

18. Wheat- Fallow- T. Aman
55

15

Land area under Percentage of net

C.P. (ha)

land under C.P. (\%)

115

$1.69 \%$

471

$6.94 \%$

4003

$58.95 \%$

385

$5.67 \%$

447

$6.58 \%$

90

$1.33 \%$

125

$1.84 \%$

455

$6.70 \%$

75

$1.10 \%$

25

$0.37 \%$

85

$1.25 \%$

18

$0.27 \%$

110

$1.62 \%$

45

$0.66 \%$

05

$0.07 \%$

$0.81 \%$

$0.22 \%$

$0.01 \%$ 
Sl. Cropping pattern (C.P.)

No.

19. Groundnut- Fallow- T. Aman

20. Coriander- Fallow- T. Aman

21. Gherkin- Fallow- T. Aman

22. Cucumber - Fallow- T. Aman

23. Mustard- Fallow- T. Aman

24. Sugarcane- Sugarcane- Sugarcane

25. Watermelon- Fallow- T. Aman

26. Garlic - Fallow-Aman

27. Onion- Fallow- T. Aman

28. Turmeric- Turmeric- Turmeric

29. Muskmelon- Fallow-Aman

30. Betel Leaf- Betel Leaf- Betel Leaf

Total
Land area under Percentage of net C.P. (ha) land under C.P. (\%) 70 $1.03 \%$ 32 $0.47 \%$ 32 $0.47 \%$ 31 $0.46 \%$ $0.22 \%$ 12 $0.18 \%$ 05 $0.07 \%$ 15 25 $0.37 \%$ 10 $0.15 \%$

$08 \quad 0.12 \%$

10 $0.15 \%$ $100 \%$

Table 2. Income range of different farmers categories.

\begin{tabular}{lllll}
\hline & \multicolumn{4}{c}{ Frequency } \\
\cline { 2 - 5 } Income range/month (Tk) & Landless & Marginal & Small & $(\%)$ \\
\hline \multirow{2}{*}{20000} & 9 & 13 & 12 & 22.6 \\
$15,000-20,000$ & 28 & 19 & 20 & 44.7 \\
$10,000-15,000$ & 15 & 14 & 23 & 34.6 \\
$5000-10000$ & 3 & 0 & 0 & 2.0 \\
\hline
\end{tabular}


Table 3. Socio-Economic status of landless farmers in different unions of Dumki upazila.

\begin{tabular}{|c|c|c|c|c|c|c|c|}
\hline $\begin{array}{l}\text { Particulars } \\
\text { Union }\end{array}$ & Age & Experience & Family size & Total Land & $\begin{array}{l}\text { Total income (Non- } \\
\text { Agri.) }\end{array}$ & Total Income (Agri.) & Total Expenditure \\
\hline Average & 49.27 \pm 3.51 & $21.35 \pm 2.90$ & $4.82 \pm 0.32$ & $47.78 \pm 2.73$ & $152,090 \pm 19,075$ & $66,758 \pm 6,328$ & $218,676 \pm 18,796$ \\
\hline Angaria & $45.45 \pm 2.50$ & $18.64 \pm 1.90$ & $3.91 \pm 0.21$ & $54.09 \pm 5.39$ & $148,454 \pm 17,302$ & $63,181 \pm 4,481$ & $221,363 \pm 14,735$ \\
\hline Lebukhali & $49.18 \pm 3.93$ & $25.45 \pm 3.77$ & $5.00 \pm 0.32$ & $44.82 \pm 1.44$ & $130,727 \pm 11,025$ & $67,181 \pm 7,631$ & $197,909 \pm 11,853$ \\
\hline Muradia & $51.45 \pm 3.98$ & $16.36 \pm 2.96$ & $5.55 \pm 0.36$ & $45.27 \pm 1.42$ & $221,454 \pm 21,448$ & $60,654 \pm 6,166$ & $282,109 \pm 25,091$ \\
\hline Pangashia & $50.91 \pm 3.39$ & $24.73 \pm 1.65$ & $4.91 \pm 0.28$ & $49.09 \pm 1.42$ & $98,000 \pm 14,000$ & $69,136 \pm 4,609$ & $175,545 \pm 12,591$ \\
\hline Sreerampur & $49.36 \pm 4.02$ & $21.55 \pm 3.46$ & $4.73 \pm 0.32$ & $45.64 \pm 0.86$ & $161,818 \pm 17,812$ & $73,636 \pm 8,461$ & $216,454 \pm 18,085$ \\
\hline
\end{tabular}

Table 4. Socio-Economic status of marginal farmers in different unions of Dumki upazila.

\begin{tabular}{|c|c|c|c|c|c|c|c|}
\hline Union & Age & Experience & Family size & Total Land & $\begin{array}{l}\text { Total income (Non- } \\
\text { Agri.) }\end{array}$ & Total Income (Agri.) & Total Expenditure \\
\hline Average & $44.78 \pm 3.19$ & $20.87 \pm 2.98$ & $5.16 \pm 0.50$ & $105.11 \pm 8.93$ & $147,200 \pm 19,231$ & $99,909 \pm 12,491$ & $244,272 \pm 18,960$ \\
\hline Angaria & $41.73 \pm 2.09$ & $22.82 \pm 2.48$ & $4.82 \pm 0.46$ & $108.91 \pm 5.76$ & $141,818 \pm 28,935$ & $121,363 \pm 12,650$ & $264,454 \pm 22,358$ \\
\hline Lebukhali & $50.36 \pm 3.49$ & $27.55 \pm 4.03$ & $6.18 \pm 0.65$ & $107.91 \pm 10.08$ & $155,454 \pm 11,186$ & $72,590 \pm 6,405$ & $229,863 \pm 15,807$ \\
\hline Muradia & $46.91 \pm 3.07$ & $21.36 \pm 2.71$ & $4.27 \pm 0.32$ & $114.55 \pm 9.82$ & $128,636 \pm 19,685$ & $136,454 \pm 12,577$ & $263,272 \pm 18,707$ \\
\hline Pangashia & $38.27 \pm 2.63$ & $14.64 \pm 1.71$ & $4.82 \pm 0.46$ & $129.00 \pm 5.52$ & $153,272 \pm 22,508$ & $100,136 \pm 12,460$ & $236,590 \pm 24,610$ \\
\hline Sreerampur & $46.64 \pm 3.96$ & $18.00 \pm 2.93$ & $5.73 \pm 0.49$ & $65.18 \pm 3.58$ & $156,818 \pm 10,066$ & $69,000 \pm 9,359$ & $227,181 \pm 12,031$ \\
\hline
\end{tabular}

Table 5. Socio-Economic status of small farmers in different unions of Dumki upazila.

\begin{tabular}{|c|c|c|c|c|c|c|c|}
\hline Union & Age & Experience & Family size & Total Land & $\begin{array}{l}\text { Total income (Non- } \\
\text { Agri.) }\end{array}$ & Total Income (Agri.) & Total Expenditure \\
\hline Average & $46.38 \pm 3.28$ & $22.44 \pm 2.60$ & $5.13 \pm 0.45$ & $212.62 \pm 18.47$ & $128,163 \pm 16,895$ & $114,818 \pm 14,491$ & $222,185 \pm 18,004$ \\
\hline Angaria & $46.82 \pm 4.07$ & $23.36 \pm 2.92$ & $4.73 \pm 0.32$ & $222.18 \pm 17.49$ & $172,909 \pm 12,612$ & $106,863 \pm 11,014$ & $228,145 \pm 22,861$ \\
\hline Lebukhali & $45.00 \pm 2.96$ & $23.09 \pm 3.53$ & $4.55 \pm 0.26$ & $230.18 \pm 26.26$ & $116,818 \pm 15,912$ & $109,363 \pm 9,320$ & $212,454 \pm 20,851$ \\
\hline Muradia & $48.91 \pm 2.77$ & $22.73 \pm 2.03$ & $5.00 \pm 0.52$ & $184.45 \pm 4.81$ & $132,727 \pm 20,312$ & $86,454 \pm 10,726$ & $201,690 \pm 17,852$ \\
\hline Pangashia & $43.55 \pm 3.47$ & $19.18 \pm 2.39$ & $4.82 \pm 0.40$ & $250.09 \pm 22.48$ & $106,545 \pm 15,482$ & $141,227 \pm 20,942$ & $226,181 \pm 14,859$ \\
\hline Sreerampur & $47.64 \pm 3.42$ & $23.82 \pm 2.16$ & $6.55 \pm 0.56$ & $176.18 \pm 6.93$ & $111,818 \pm 16,689$ & $130,181 \pm 15,695$ & $242,454 \pm 13,649$ \\
\hline Grand Total & $46.81 \pm 3.34$ & $21.55 \pm 2.82$ & $5.04 \pm 0.43$ & $121.84 \pm 20.85$ & $142,484 \pm 18,501$ & $93,828 \pm 12,612$ & $228,378 \pm 18,695$ \\
\hline
\end{tabular}


Table 6. Distribution of problems faced by the farmers in a rank order.

\begin{tabular}{lll}
\hline Problems & Citation & Rank \\
\hline Lack of improved varieties of seed & 110 & 1 \\
\hline The high price of farm inputs & 75 & 2 \\
\hline Lack of skilled labour in proper time & 65 & 3 \\
\hline An infestation of insect and pest & 62 & 4 \\
\hline Unavailability of input dealer & 50 & 5 \\
\hline Lack of agricultural machinery & 42 & 6 \\
\hline Scarcity of irrigation water & 40 & 7 \\
\hline Lack of organizational support & 38 & 8 \\
\hline Lack of information from agriculture officers & 35 & 10 \\
\hline Lack of training facilities & 32 & 11 \\
\hline Lack of credit facilities & 28 & 12 \\
\hline Lack of adequate transport facilities & 22 & 13 \\
\hline Lack of proper market facilities & 10 & 15 \\
\hline Stealing of crops & 2 & \\
\hline
\end{tabular}

\section{Conclusions}

On the basis of findings and its logical interpretation it can be conclude that most of the farmers of Dumki were not well educated and have medium family size. Cereal crops were the major crops of that village and limited number of vegetables were grown in homestead area for their own consumption and selling purpose. The major crops grown during Kharif were B. Aus, T. Aus, T. Aman; during Robi were Boro rice, Soybean, Mungbean, Grasspea, Cowpea, Lentil, Groundnut, Chilli and summer and winter vegetables are grown limitedly. Farmers were willing to take the modern technology. The farmers, who have increased the degree of organizational participation and extension contact, have confronted slight problems in vegetable cultivation. Before taking a broad program for increasing vegetable production, this factor must be taken into consideration.

\section{Acknowledgements}

The authors want to express their sincere gratitude to all the farmers for participating in the study. We express our deepest appreciation and heartfelt thanks to all of officials in Department of Agricultural Extension, Dumki, Patuakhali, Bangladesh for conducting several meetings with so many farmers.

\section{Conflict of interest}

None to declare.

\section{Authors' contribution}

Tusher Chakrobarty: Conceptualization, Data correction, Writing - original draft. Shahin Imran: Data correction, Writing - original draft. Md. Musfiqur Rahman, Md. Golam Rahman \& Jhutan Chandra Sarker: Investigation, Writing - review \& editing. Md. Rezaul Karim \& Md. Niaz Morshed: Resources, Formal analysis. Md. Al Emran Hossain, Naim Mustafa Ali \& Golam Mustafa Chowdhury: Investigation, Writing review \& editing. Md. Asif Mahamud: Methodology, Formal analysis, Writing - review \& editing. All authors have read and approved the final manuscript.

\section{References}

Awal MA and MAH Khan, 2020. Global Warming and Sea Level Rising: Impact on Agriculture and Food Security in Southern Coastal Region of Bangladesh. Asian J. Geogr. Res., 3: 9-36.

Bangladesh Bureau of Statistics (BBS), 2010. Census of agriculture 2008: Structure of agricultural holdings and livestock population.

Banglapedia, 2008. National Encyclopedia of Bangladesh. Asiatic Society of Bangladesh.

Biswas AA, MT Islam, MA Sattar, SN Mili and TJahan, 2015. Community Based Risk Assessment of Agriculture Sector in Sreerampur Union of Bangladesh. J. Food Secur., 3: 125-136.

FAO, 2014. Report on In-depth Capacity Assessment of Bangladesh to Produce Agricultural and Rural Statistics: Implementation of Global Strategy to Improve Agricultural and Rural Statistics

FAO, 2017. The future of food and agriculture-Trends and challenges. Annual Report. 
Ghose B, B Razib and G Sharmistha, 2014. Reviewing the status of agricultural production in Bangladesh from a food security perspective. Russ. J. Agric. Soc., 25: 19-27.

Haque MA, 1995. Problem Confrontation of the Members of Mohila Bittaheen Samabaya Samittee working under the Bangladesh Rural Development Board. M.S. (Ag. Ext. Ed.) Thesis, Department of Agricultural Extension Education, Bangladesh Agricultural University, Mymensingh.

Hossain MJ, MZ Haque, R Satyajit, M Moniruzzman and Z Rahman, 2015. Impact of climate change on agriculture in the tidal flood plain area of Dumki upazila, Patuakhali, Bangladesh. Am. Research Thoughts, 1: $2492-2512$.

Household income and Expenditure Survey (HIES), 2010. Bangladesh Bureau of Statistics.Statistics division, Ministry of planning, Bangladesh.

Islam MMU, PS Saha, T Chakrobarty, NK Saha, MS Islam and MA Salam, 2017. Genetic diversity of aromatic rice in Bangladesh. Res. Agric., Livest. Fish., 4: 1-6.

Islam MT, M Siddeqa and AAABiswas, 2018. Smallholder Farmer's Knowledge, Perception and Attitude on Occupational Hazard and Safety at Dumki Sub-District of Bangladesh. J. Soci. Anthr., 2: 21-26.

Islam S, 2003. Banglapedia: national encyclopedia of Bangladesh (Vol. 3). Asiatic society of Bangladesh.

Kabir R, HT Khan, E Ball and K Caldwell, 2016. Climate change impact: the experience of the coastal areas of Bangladesh affected by cyclones Sidr and Aila. J. Environ. Public Health, Article ID 9654753.

Manik IH, MA Abedin, MR Rahman, T Chakrobarty, SB Jaman, M Al Noor and R Sultana, 2016. Reducing urea demand for rice crop through foliar application of urea in boro season. Res. Agric., Livest. Fish., 3: 7985 .

Mondal S, MGR Akanda and AS Haque, 2020.Determinants of Farmers' Level Crop Productivity at Dumki Upazila under Patuakhali District. Asian Journal of Agricultural Extension, Economics \& Sociology, 38: 78-86.

Palash MS and S Bauer, 2017. Diversification of farmland use in Bangladesh: land allocation impacts on farm profitability. Open Agriculture, 2: 175-188.

Quasem MA, 2011. Conversion of agricultural land to non-agricultural uses in Bangladesh: extent and determinants. Bangladesh Development Studies, Bangladesh Institute of Development Studies (BIDS), 34: 59-85.

Rahman MM, MP Chowdhury and S Islam, 2016. Socio-Economic status of fish farmers in DhumkiUpazila under Patuakhali District, Bangladesh. Int.J. Fish. Aquat., 4: 288-292.

Rashid MH, MAJ Bhuyan and MNA Sarder, 2020. Research Highlights of the Competitive Research Grant (CRG) Sub-Projects, Project Implementation Unit (PIU)-BARC, National Agricultural Technology ProgramPhase II Project (NATP2), Bangladesh Agricultural Research Council (BARC), New Airport Road, Farmgate, Dhaka - 1215, Bangladesh.

Rashid MU and MM Islam, 2011. Women s Participation in Family Decision Making in Dumki Upazila of Patuakhali District. The Agriculturists, 9: 137-142.

Statistical Tool for Agricultural Research (STAR), 2013. Version: 2.0.1, International Rice Research Institute (IRRI), Philippines.

World Bank, 2016. Bangladesh: Growing the Economy Through Advances in Agriculture. 